\title{
Seasonal pattern in browsing trees and shrubs by reintroduced Cuvier's gazelles: a study in Morocco with management implications
}

\author{
Saâd Hanane ${ }^{1}$ (D) Zouheir Amhaouch ${ }^{2}$
}

Received: 31 December 2020 / Revised: 18 March 2021 / Accepted: 4 May 2021 / Published online: 12 May 2021

(c) The Author(s), under exclusive licence to Springer-Verlag GmbH Germany, part of Springer Nature 2021

\begin{abstract}
Cuvier's gazelle (Gazella cuvieri) was reintroduced in Tergou reserve (TR) in 2018-2019 to help restore its population at the Moroccan Central Plateau. A study on browsing trees and shrubs was conducted in this reserve to identify (i) the seasonal pattern of this activity and (ii) the most solicited tree and shrub species. Here, we used six random 500-m transects to collect, each month and at each transect, the number of fresh browsing traces of each encountered tree and shrub species. We used principal component analysis (PCA) and linear regression model (LM) to test seasonal variation of the composition of trees and shrubs browsed. Our results showed that, in this reserve, Olea europaea, Quercus ilex, Cistus salviifolius, and Cistus creticus are mostly browsed during winter, whereas Tetraclinis articulata and Ruta angustifolia are mainly used during spring. This information is useful to the managers of the TR not only to consider the importance of the aforementioned trees and shrubs for reintroduced gazelles but also to take the necessary measures so that the forest stand of this reserve is maintained at an appropriate level. Thus, the pursuit of monitoring is necessary to understand the bio-ecology of this semicaptive population more deeply. For this reason, the TR remains a useful and appropriate reference framework offering the opportunity for consolidating and improving the knowledge on this vulnerable mammal species in the view of a future successful release in the wild.
\end{abstract}

Keywords Forest stand $\cdot$ Reintroduction $\cdot$ Gazella cuvieri $\cdot$ Diet $\cdot$ Management

\section{Introduction}

Cuvier's gazelle, Gazella cuvieri, is among the endemic mammal species of North Africa. Currently, this Bovidae is listed as "vulnerable" by the IUCN (IUCN 2018). In Morocco, this species is categorized among protected species by the law on the protection of species of flora and wildlife and the control of their trade (law 29-05, adopted in 2011) and the law on the hunting control (Dahir of July 21, 1923 on the hunting police). It is exclusively distributed in three North African countries,

This paper is dedicated to the memory of Mr. Said Hajib who sadly passed away on Monday November 2th, 2020

Saâd Hanane

sdhan333@gmail.com

1 Forest Research Center, Department of Water and Forests, Avenue Omar Ibn El Khattab, BP 763, 10050 Rabat, Agdal, Morocco

2 Parks and Natural Reserves Division, Department of Water and Forests, No 3, Rue Haroun Errachid, Agdal, Rabat, Morocco namely Morocco, Algeria, and Tunisia (Beudels et al. 2013; Gil-Sánchez et al. 2016). In Morocco, the distributional range of the natural populations is limited to three regions, namely, (i) Bas-Drâa-Aydar (935 animals, 597-1607) (GilSánchez et al. 2016; IUCN 2018), (ii) west of the Anti-Atlas (1000-2000) (Cuzin 2015a; IUCN 2018), and (iii) the eastern part of the country, with small dispersed populations (around 300) (IUCN 2018). The total estimation of the Moroccan natural population ranged between 1900 and 3900 individuals (IUCN 2018). According to IUCN (2018), the reduction in the G. cuvieri population is due to three factors, namely poaching, predation, and habitat loss. Given this situation, the reestablishment of a viable breeding population is desired to restore its favorable conservation status. Consequently, as part of its strategic efforts to strengthen wildlife populations, Morocco's Water and Forest Department, in collaboration with the Emirates Center of Wildlife Propagation and Al Maha Farm, carried out a Cuvier's gazelle reintroduction program in CentralPlateau, in the Tergou reserve (hereafter TR) (24 Cuvier's gazelles released: 12 in November 2018, 6 in December 2018, 3 in February 2019, and 3 in July 2019). 
Establishing monitoring programs to assess the reintroduction efforts is an unmissable step towards understanding the processes of population evolution within the protected release areas (i.e., national parks and reserves). The demographic trends, population structure and dynamic, as well as species-habitat interactions are all axes to develop for efficient and suitable management of reintroduced species. Nowadays, managers are convinced of the relevance of setting up a monitoring system and that without it, they will not be able to know whether the reintroduction operations have succeeded or failed. This is the case, for instance, in North Africa, where post-release monitoring programs have been carried out for some threatened species, such as doublespurred francolin (Francolinus bicalcaratus ayesha) in Sidi Allal Al Bahraoui game reserve (Hanane and Magri 2016), dorcas gazelle (Gazella dorcas) in M'Sabih Talaa Reserve (Ait Baamrane et al. 2012, 2013), aoudad (Ammotragus lervia) in Amassine reserve (Ramzi et al. 2018), Atlas deer (Cervus elaphus barbarus) in Tazekka National Park (Ismaili et al. 2018), and mhorr gazelle (Nanger dama mhorr) in Safia reserve (Abaigar et al. 2019).

Although on the right path, the research to be developed in protected areas deserves a special attention. For example, the diet of the reintroduced mammal species remains to date under-studied. Indeed, except for the dorcas gazelle in M'Sabih Talaa Reserve (Ait Baamrane et al. 2012, 2013) and Atlas deer in Tazekka National Park (Ismaili et al. 2018), no other studies have been conducted on this subject despite its paramount to inform on the real dietary needs of ungulates in the reintroduced areas.

In this context, the importance of trees and shrubs in the gazelles' dietary must be assessed, as it has been the case in northern Algeria for the Cuvier's gazelle (Benamor et al. 2019), and other gazelle species, such as the Dama gazelle (Gazella dama) (Grettenberger and Newby 1986), dorcas gazelle (Grettenberger 1987; Ait Baamrane et al. 2012), and Acacia gazelle (Gazella acaciae) (Breslau et al. 2020).

The present study aimed to assess the possible presence of a seasonal pattern in using different tree and shrub species as food resources by the reintroduced Cuvier's gazelles and identify the composition of the most browsed species in the Tergou reserve (TR). The results of this investigation might be useful to improve the management (in situ) and conservation (ex situ) of this vulnerable mammal species.

\section{Materials and methods}

\section{Study area}

The study was conducted in the TR, a 118-ha enclosed forest located in the Central-plateau, in north-central Morocco $\left(33^{\circ} 26^{\prime} 34^{\prime \prime} \mathrm{N}, 6^{\circ} 7^{\prime} 39^{\prime \prime} \mathrm{E}\right)$ (Fig. 1). The TR, located on a steep mountain side at between 544 and $1053 \mathrm{~m}$ asl, was created in 1998 to conserve the ungulates that were historically present in north-central Morocco. The study area has a subhumid climate characterized by wet and relatively cold and rainy winters (average $=773.2 \mathrm{~mm}, \mathrm{SD}=25.1$ ) and hot and dry summers (average $\left.=38^{\circ} \mathrm{C}, \mathrm{SD}=2.11\right)(\mathrm{Cuzin} 2015 \mathrm{~b}$; Haraz 2020).

To meet the needs of reintroduced gazelles, a water tower was established inside the TR (Fig. 1), in addition to a track connecting the summit and the base of the mountain side (Fig. 1). The fence surrounding the TR is $5024.76 \mathrm{~m}$ long. In this reserve, the forest stand is very homogeneous with a dominance of Olea europaea, Quercus ilex, Tetraclinis articulata, Buxus balearica, Phillyrea latifolia, Cistus salviifolius, Cistus creticus, and Chamaerops humilis. The landscape around the TR is dominated by the same forest type, cerealiculture especially Barley (Hordeum vulgare), and the culture of an aromatic and medicinal plant, i.e., lavender (Lavandula angustifolia).

The TR is relatively isolated from the humans, with the nearest habitation from the fence located at $3.25 \mathrm{~km}$.

\section{Data collection}

The data on browsing activity were collected between June 2019 and May 2020 monthly along six 500-m transects. At the very beginning of our fieldwork, these transects were randomly established in the Tergou enclosure using the QGIS random selection tool (Quantum GIS Development Team 2017). Then, they were fixed for the monthly counting of the number of browsing signs during the study period. Monthly observations were pooled and presented as seasonal observations as follows: summer (end June to August), autumn (end September to November), winter (end December to February), and spring (end March to May) (because of the lockdown established in Morocco between March and June 2020 due to the COVID-19 pandemic, the data collection during spring was performed by the same field assistant, who has good knowledge on the vegetation species of the Tergou reserve). Observation periods were restricted to daytime hours in the four seasons: $0600-2000 \mathrm{~h}$ (summer), 0700-1900 h (autumn), 0800-1800 h (winter), and 0500-2000 h (spring).

At each monthly passage along the six transects, we carefully and visually checked all tree and shrub species (predominantly growing higher than $0.5 \mathrm{~m}$ ) present along the 500-m transect on a 5-m band on either side. This direct visualization approach is commonly used in the study and identification of browsed species (Chevrier et al. 2012; Mahenya et al. 2016; Borkowski et al. 2017; 


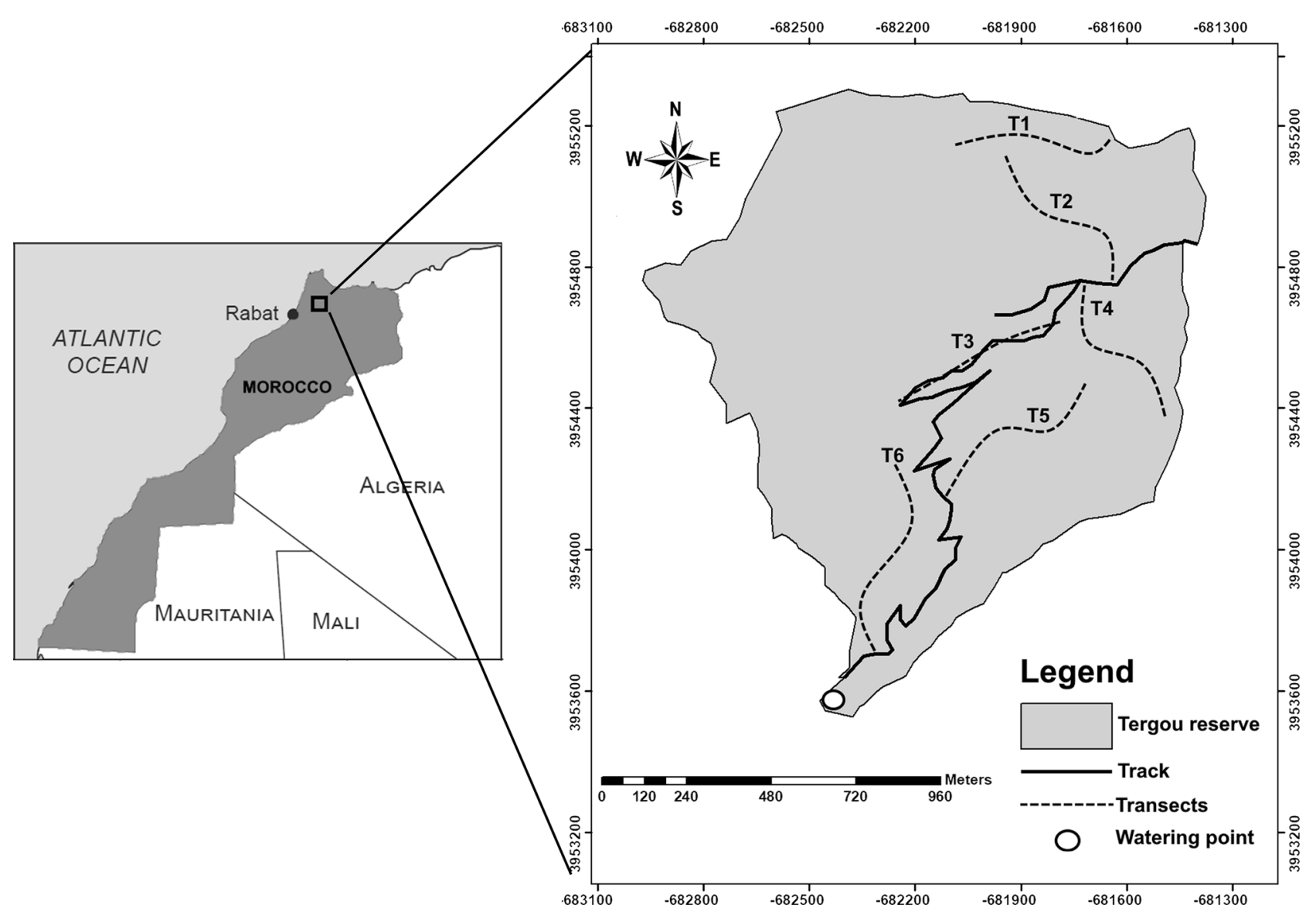

Fig. 1 Map showing the geographic location of the Tergou reserve in Morocco and the position of the six transects in this protected area

Breslau et al. 2020; Chebli et al. 2020). The cumulative number of the fresh browsing traces (the color of the sectioned part of the plant is still green; Fig. 4a, b) was thus recorded for each tree and shrub species in each of the six 500-m transects in the twelve study-months. The parts of the plants formerly sectioned were not considered (i.e., become brown). The use of this methodological approach was made possible due to the presence of a single herbivorous vertebrate species in this enclosure, i.e., the Cuvier's gazelle.

\section{Statistical analyses}

A principal component analysis (PCA) was first performed to summarize the 12 initial browsed tree and shrub species into a few representative and independent factors. For each PCA, a varimax normalized rotation was applied to the set of principal components with eigenvalues $>1.0$ to obtain simpler and more interpretable gradients (Legendre and Legendre 1998). After this first stage of analysis, we performed a parametric linear regression model (LM) on PCA axes (i.e., on the identified tree and shrub species groups) to investigate the seasonal variation in the browsing of trees and shrubs in this forest reserve. Pairwise post hoc Tukey's tests were conducted to determine significant differences between seasons. The normality distribution of the residuals of all regression models was verified using the Shapiro-Wilk test. All statistical analyses were performed in R-4.0.3 software (R Development Core Team 2018). We used the packages "ade4" (Dray and Duffour 2007) and "Agricolae" (Mendiburu 2010) to perform the PCA and post hoc Tukey's tests, respectively. To plot the relationship between the predictive PCA axes as function of the four seasons, the "ggplot2" package (Wickham 2016) was used. Means are quoted \pm standard errors. 
Table 1 Pearson correlation coefficients and associated $P$ values of the three factors extracted from the PCA with the original browsed tree and shrub species

\begin{tabular}{lllllll}
\hline Species & PC1 & \multicolumn{3}{c}{ PC2 } & \multicolumn{3}{c}{ PC3 } \\
& $r$ & $p$ & $r$ & $p$ & $r$ & $p$ \\
\hline Olea europaea & $\mathbf{0 . 7 6 3}$ & $\mathbf{0 . 0 1 0}$ & -0.096 & 0.793 & -0.484 & 0.156 \\
Buxus balearica & 0.155 & 0.155 & 0.266 & 0.457 & $-\mathbf{0 . 7 9 9}$ & $\mathbf{0 . 0 0 6}$ \\
Phillyrea latifolia & 0.418 & 0.228 & 0.114 & 0.692 & 0.177 & 0.714 \\
Quercus ilex & $\mathbf{0 . 7 3 6}$ & $\mathbf{0 . 0 1 5}$ & -0.084 & 0.819 & 0.061 & 0.867 \\
Tetraclinis articulata & -0.124 & 0.733 & $\mathbf{0 . 9 3 1}$ & $\mathbf{0 . 0 0 0}$ & -0.181 & 0.616 \\
Ruta angustifolia & -0.100 & 0.784 & $\mathbf{0 . 9 0 4}$ & $\mathbf{0 . 0 0 0}$ & -0.017 & 0.963 \\
Pistacia lentiscus & 0.221 & 0.540 & 0.022 & 0.952 & $\mathbf{0 . 8 1 3}$ & $\mathbf{0 . 0 0 4}$ \\
Cistus salviifolius & $\mathbf{0 . 8 0 3}$ & $\mathbf{0 . 0 0 5}$ & -0.298 & 0.404 & 0.422 & 0.225 \\
Cistus creticus & $\mathbf{0 . 8 6 5}$ & $\mathbf{0 . 0 0 1}$ & -0.277 & 0.438 & 0.311 & 0.381 \\
Chamaerops humilis & $\mathbf{0 . 6 4 6}$ & $\mathbf{0 . 0 4 4}$ & -0.247 & 0.492 & 0.287 & 0.422 \\
Jasminum fruticans & 0.551 & 0.101 & -0.118 & 0.701 & 0.267 & 0.429 \\
Daphne gnidium & $\mathbf{0 . 6 6 1}$ & $\mathbf{0 . 0 3 3}$ & -0.267 & 0.574 & 0.307 & 0.399 \\
Eigenvalue & 3.031 & & 1.997 & & 1.928 & \\
Variance explained (\%) & 33.678 & & 22.196 & & 21.421 & \\
Cumulative variance explained (\%) & 33.678 & & 55.873 & & 77.294 & \\
\hline
\end{tabular}

\section{Results}

In total, twelve tree and shrub species were browsed in the Tergou reserve from summer 2019 to spring 2020, among which four are trees and eight are shrubs (Table 1). When combining the four seasons, the browsing intensity is significantly different between the four tree species $\left(\mathrm{Chi}^{2}=24.671, d f=3, P<0.001\right)$, being more focused on Olea europaea than on Phillyrea latifolia $(P=0.001)$ (Table 2), Quercus ilex $(P=0.001)$ (Table 2), and Tetraclinis articulata $(P=0.001)$ (Table 2$)$. The browsing intensity is not significant between the eight shrub species $\left(\mathrm{Chi}^{2}=7.203, d f=7, P=303\right)$.

Based on the results of the PCA, the twelve browsed tree and shrub species were summarized into three independent factors that accounted for $77.3 \%$ of the variance and whose eigenvalues exceeded one. The first factor $\left(\mathrm{PC}_{1}: 33.7 \%\right)$ represents an axis of a positive use of Olea europaea, Quercus ilex, Cistus salviifolius, Cistus creticus and of negative use of Chamaerops humilis, and Daphne gnidium (Table 1). The second factor $\left(\mathrm{PC}_{2}: 22.2 \%\right)$ was positively associated with the use of Tetraclinis articulata and Ruta angustifolia (Table 1 ), while the third factor $\left(\mathrm{PC}_{3}: 21.4 \%\right)$ was positively associated with the use of Pistacia lentiscus and negatively with Phillyrea latifolia (Table 1). The Kaiser-Meyer-Olkin measure of sampling adequacy (KMO) indicated that our data were suitable for the PCA (PCA: $\mathrm{KMO}=0.217$; Bartlett test for sphericity, $\left.\mathrm{Chi}^{2}=63.252, p=0.003\right)$.

Because $\mathrm{PC}_{1}$ (Wilk-Shapiro test: $w=0.957, p=0.752$ ), $\mathrm{PC}_{2}(w=0.848, p=0.055)$, and $\mathrm{PC}_{3}(w=0.887, p=0.155)$
Table 2 Mean $( \pm$ SD) number of browsing contacts per tree and shrub species and per transect of $500 \mathrm{~m}$ in the Tergou reserve, Morocco

\begin{tabular}{llllll}
\hline Species & \multicolumn{2}{l}{ Seasons } & & & \\
\cline { 2 - 5 } & Summer & Autumn & Winter & Spring & \multirow{2}{*}{ All seasons combined } \\
\hline Olea europaea & $4.73 \pm 1.72$ & $5.25 \pm 0.07$ & $6.77 \pm 0.25$ & $5.20 \pm 3.11$ & $5.54 \pm 1.58$ \\
Buxus balearica & $0.57 \pm 0.40$ & $0.70 \pm 0.71$ & $1.10 \pm 0.96$ & $0.85 \pm 0.21$ & $0.81 \pm 0.60$ \\
Phillyrea latifolia & $0.69 \pm 0.25$ & $0.65 \pm 0.15$ & $0.77 \pm 0.27$ & $0.48 \pm 0.15$ & $0.65 \pm 0.12$ \\
Quercus ilex & $0.23 \pm 0.06$ & $0.20 \pm 0.09$ & $0.87 \pm 0.40$ & $0.85 \pm 0.78$ & $0.60 \pm 0.43$ \\
Tetraclinis articulata & $0.17 \pm 0.15$ & $0.40 \pm 0.10$ & $0.20 \pm 0.17$ & $0.65 \pm 0.21$ & $0.26 \pm 0.20$ \\
Ruta angustifolia & $0.00 \pm 0.00$ & $0.00 \pm 0.00$ & $0.07 \pm 0.12$ & $0.55 \pm 0.32$ & $0.16 \pm 0.27$ \\
Pistacia lentiscus & $0.17 \pm 0.15$ & $0.90 \pm 0.85$ & $0.10 \pm 0.17$ & $0.00 \pm 0.00$ & $0.26 \pm 0.46$ \\
Cistus salviifolius & $0.07 \pm 0.12$ & $1.10 \pm 1.56$ & $2.27 \pm 2.44$ & $0.35 \pm 0.07$ & $1.09 \pm 1.61$ \\
Cistus creticus & $0.10 \pm 0.08$ & $1.00 \pm 1.41$ & $1.93 \pm 0.93$ & $0.15 \pm 0.21$ & $0.81 \pm 1.08$ \\
Chamaerops humilis & $1.00 \pm 1.04$ & $1.10 \pm 0.57$ & $0.07 \pm 0.12$ & $0.70 \pm 0.99$ & $0.68 \pm 0.77$ \\
Jasminum fruticans & $0.56 \pm 0.15$ & $0.41 \pm 0.10$ & $0.79 \pm 0.29$ & $0.15 \pm 0.09$ & $0.48 \pm 0.27$ \\
Daphne gnidium & $0.06 \pm 0.10$ & $0.25 \pm 0.21$ & $0.43 \pm 0.26$ & $0.15 \pm 0.11$ & $0.22 \pm 0.16$ \\
\hline
\end{tabular}


Table 3 Summary of the results of regression analyses (LM) on $\mathrm{PC}_{1}$, $\mathrm{PC}_{2}$, and $\mathrm{PC}_{3}$ as functions of the four seasons

\begin{tabular}{lcccc}
\hline Variable & $\beta \pm \mathrm{SE}$ & $t$ ratio & $P$ value & Model validation** \\
\hline $\mathrm{PC}_{1}: R^{2}=0.75, F_{3,7}=6.14, P=0.029$ & & \\
Intercept & $-0.97 \pm 0.35$ & -2.77 & 0.032 & $w=0.91, P=0.30$ \\
Autumn & $0.91 \pm 0.55$ & 1.64 & 0.151 & \\
Winter & $2.11 \pm 0.50$ & 4.25 & $0.005^{*}$ & \\
Spring & $0.78 \pm 0.55$ & 1.41 & 0.207 & \\
$\mathrm{PC}_{2}: R^{2}=0.83, F_{3,7}=10.08, P=0.009$ & \\
Intercept & $-0.61 \pm 0.29$ & -2.11 & 0.079 & $w=0.85, P=0.06$ \\
Autumn & $0.32 \pm 0.45$ & 0.71 & 0.502 & \\
Winter & $0.21 \pm 0.41$ & 0.65 & 0.542 & \\
Spring & $2.32 \pm 0.45$ & 5.11 & $0.002^{*}$ & \\
PC $R_{3}: R^{2}=0.360, F_{3,7}=1.12, P=0.412$ & \\
Intercept & $-0.17 \pm 0.57$ & -0.30 & 0.772 & $w=0.97, P=0.87$ \\
Autumn & $1.25 \pm 0.89$ & 1.40 & 0.212 & \\
Winter & $-0.35 \pm 0.80$ & -0.44 & 0.675 & \\
Spring & $0.14 \pm 0.59$ & 0.16 & 0.881 & \\
\hline
\end{tabular}

*Significant effects $(P<0.05)$ are displayed in boldface font; **WilkShapiro test on the residuals of the model

are normally distributed, we used the parametric linear regression model for assessing the relationships between the three axes (i.e., $\mathrm{PC}_{1}, \mathrm{PC}_{2}$, and $\mathrm{PC}_{3}$ ) and the four seasons (i.e., summer, autumn, winter, and spring). Our model results showed that $\mathrm{PC}_{1}$ varies significantly with the seasons (Table 3), being higher in winter than summer (Tukey's post hoc test: $95 \%$ confidence interval (CI): 0.392-3.825; $P=0.020$ ), autumn (95\% CI: $0.162-3.621 ; P=0.041)$, and spring (95\% CI: 0.201-3.699; $P=0.038$ ) (Table 2; Fig. 2a). $\mathrm{PC}_{2}$ also varies significantly with season (Table 3 ), being higher in spring compared to summer (95\% CI: 0.748-3.898; $P=0.008$ ), autumn (95\% CI: $0.273-3.724 ; P=0.027$ ), and winter (95\% CI: 0.485-3.635; $P=0.016$ ) (Table 3; Fig. 2b). This finding suggests that Olea europaea, Quercus ilex, Cistus salviifolius, and Cistus creticus are mostly browsed in winter, whereas Tetraclinis articulata and Ruta angustifolia $\left(\mathrm{PC}_{2}\right.$ axis) are rather browsed during spring (Table 3; Fig. 2a, b). However, species composing the $\mathrm{PC}_{3}$ axis (i.e., Pistacia lentiscus and Phillyrea latifolia) show no variation in the browsing intensity during the four seasons (Table 3 ). The residuals of the three seasonal models (i.e., $\mathrm{PC}_{1}, \mathrm{PC}_{2}$, and $\mathrm{PC}_{3}$ ) follow a normal distribution, thereby suggesting a good fitting of the data (Table 3).

Detailed examination of $\mathrm{PC}_{1}-\mathrm{PC}_{2}$ space shows that seasons are clearly separated on the first and second axes (Fig. 3). Gazelles mostly use the tree and shrub species composing the $\mathrm{PC}_{1}$ axis in winter (Fig. 3) and those composing the $\mathrm{PC}_{2}$ axis in spring (Fig. 3).
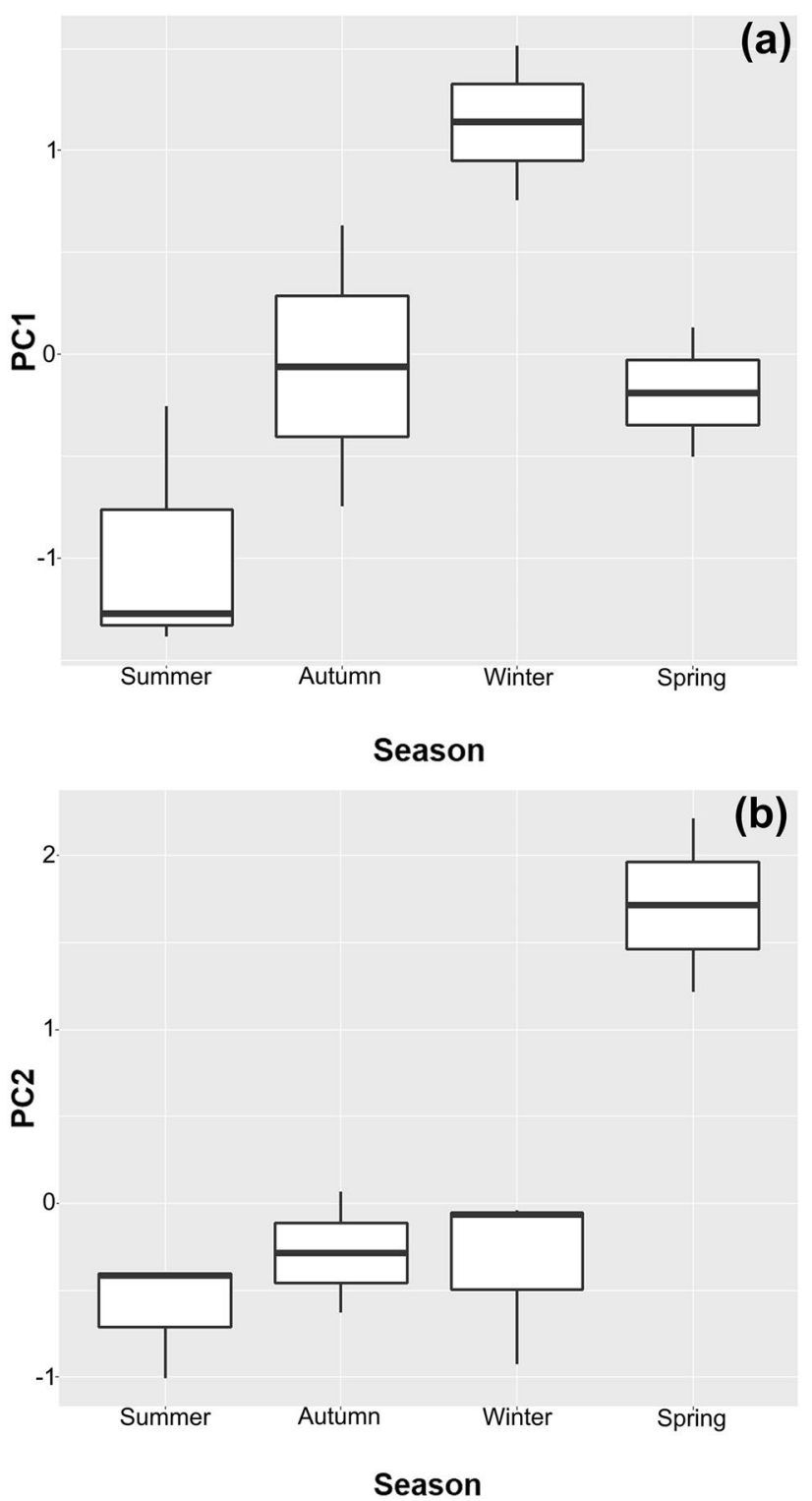

Fig. 2 Variation of $\mathrm{PC}_{1}$ and $\mathrm{PC}_{2}$ axes according to the four seasons

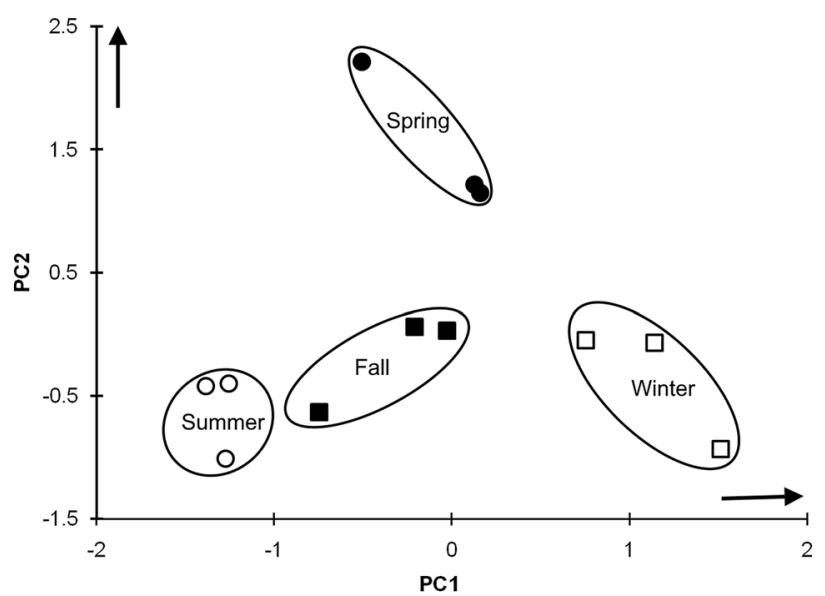

Fig. 3 Distribution of the four seasons in PC1-PC2 distribution space derived from the PCA of the original variables. The black and white squares and circles are the grouped values of $\mathrm{PC} 1$ and $\mathrm{PC} 2$ per season 
Fig. 4 Trace of Cistus creticus (a) and Pistacia lentiscus (b) browsing
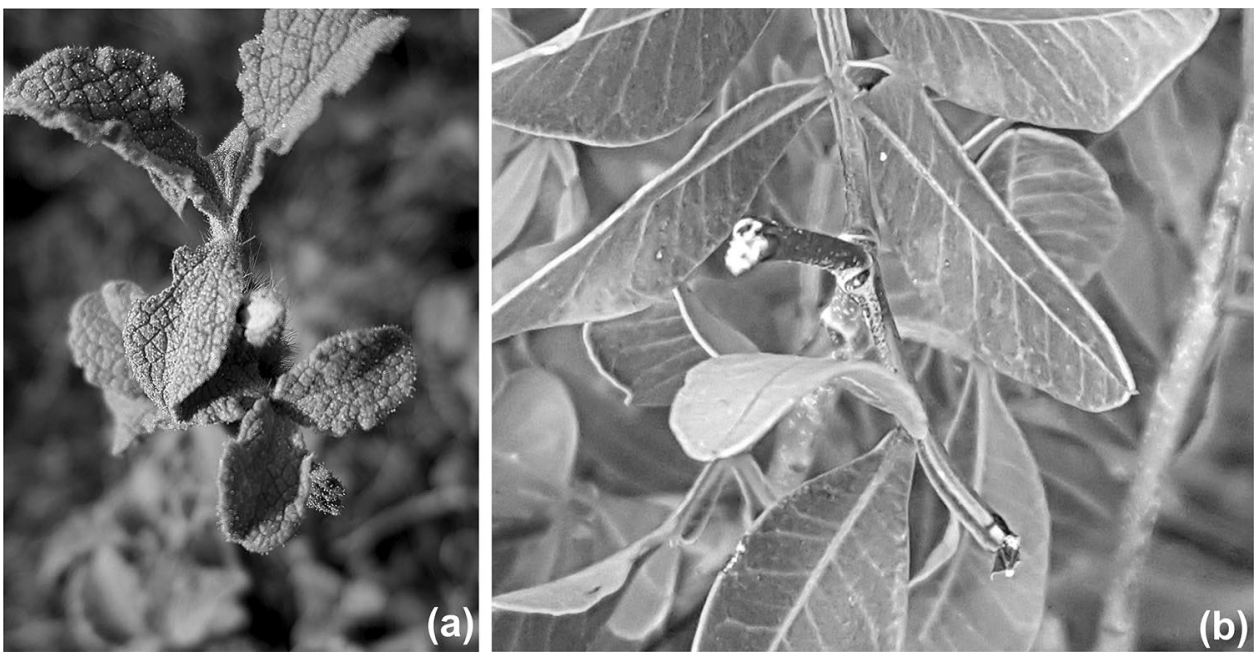

\section{Discussion}

In the present study conducted in the TR, we investigated browsing tree and shrub species by reintroduced Cuvier's gazelles. Our results demonstrate the presence of a seasonal pattern in the browsing activity, being dependent mainly on Olea europaea, Quercus ilex, Cistus salviifolius, and Cistus creticus in winter and on Tetraclinis articulata and Ruta angustifolia in spring. Shrubs and trees are thus essential for Cuvier's gazelles as it has also been demonstrated in Algeria by Chahrazad and Dhaouia (2013) and Benamour et al. (2019). They are also known to be important food components for other gazelle species such as the Mhorr (Abaigar et al. 1997) and Dorcas gazelles (Ait Baamrane et al. 2012, 2017).

The relative use of Olea europaea, Quercus ilex, Cistus salviifolius, and Cistus creticus as fodder resources in winter is a direct consequence of the first rains and the marked decrease of herb biomass. In studying the seasonal diet of Dorcas gazelles in Morocco, Loggers (1991) evoked the existence of a negative relationship between the biomass availability and the use of shrubs. Indeed, according to this author, as biomass decreases, the use of shrubs as food resources increases. This seems the case in the TR since, during winter, the herbaceous layer has not developed yet. The low availability of forage resources in the winter period was also reported by Nordengren et al. (2003), in studying the availability and quality of winter browse in herbivores, and Hygnstrom et al. (2009), when studying browsing in the White-tailed Deer. The use of trees as forage resources by Cuvier's gazelles in winter is well known (IUCN 2018). Tree species, such as Pinus halepensis, Cupressus spp., and Quercus ilex, are often used (Chahrazed and Dhaouia 2013; IUCN 2018).

In the TR, the Cuvier's gazelle mainly browses wild olive trees as is the case in Algeria in the Mergueb Nature Reserve
(Bouredjli 1989; de Smet 1991; Sellami 1999) and in Djebel El Achch (Talbi 1989), and Tunisia in the Boukornine National Park (Abaigar et al. 2005). Holm oak trees also constitute a forage resource for this ungulate (Cristobal 2006; Arbouche et al. 2012; IUCN 2018; Benamor et al. 2019). The browsing of these aforementioned tree species would be favored by their specific characteristics, namely the small heights (in the TR) and the important foliage at the lowest part of the canopy. This is in agreement with Goodman (1975), who, in studying the relationship between vegetation structure and its use by wild herbivores, showed that browse use depends on tree height that is between the ground and $1 \mathrm{~m}(15.5 \%)$. The use of shrub species belonging to the Cistaceae family as a food resource by Cuvier's gazelles during winter is relatively common. Indeed, in the Algerian mountain of Djebel Messaâd, 16.7\% of the Cuvier's gazelle winter diet featured Cistus libanotis (Benamour et al. 2019). This has been reported for other ungulate species, as this was the case of $C$. salviifolius for (i) the European roe deer (Capreolus capreolus) (Wallach et al. 2010), (ii) the Atlas deer (Cristobal 2006; Ismaili et al. 2018), and (iii) aoudad, the case of $C$. ladanifer for aoudad (Cristobal 2006), and Helianthemum lipii for the mountain gazelle (Gazella gazella) (Campbell 1997).

In spring, the reintroduced Cuvier's gazelles browse mainly Tetraclinis articulata and Ruta angustifolia. In the TR, these two plant species are available in areas with good herbaceous vegetation coverages. We thus suspect that the browsing of these two species is associated with their presence at the time when using the herbaceous layer as a food resource rather than a particular attraction. This is all the more true that herbaceous layer development is at its maximum in this reserve compared to the winter period. Benamor et al. (2019), in studying the seasonal diet of Cuvier's gazelles in Northern Algeria, have evoked the importance of grasses in the spring diet of this ungulate (22\%). This has also been confirmed for the Dorcas gazelle by Ait Baamrane et al. (2017), who have 
stressed the importance of some herbaceous layer species in the spring diet $(53.1 \%)$ compared to grasses $(22.3 \%)$ and mostly to shrubs $(8.1 \%)$.

Overall, the use of trees and shrubs as food resources by Cuvier's gazelles would be tributary to the herbaceous understory availability, and that its availability level (recovery) would influence the important use of trees and shrubs as food resources in the TR.

\section{Conclusions and management implications}

In short, the distribution of browsing by tree and shrub species according time has pointed out a marked use during the winter and to a much lesser degree during spring.

To optimize future Cuvier's gazelle release into the wild programs, it is necessary to choose areas with good availability of forest trees (such as Olea europaea, Quercus ilex, Quercus suber, Buxus balearica, Tetraclinis articulata, and Pistacia lentiscus) and shrubs (like Cistus salviifolius, Cistus creticus, and Ruta angustifolia). This choice would be beneficial when the herbaceous understory is relatively unavailable due to the persistence of drought effect most often recorded in this part of the Mediterranean.

Our findings highlight the need for future works to (i) quantify the seasonal significance of the herb layer species in the diet of Cuvier's gazelles, (ii) know whether there is a trade-off between the use of trees and shrubs on the one hand, and that of herbaceous species in the diet of the Cuvier's gazelles on the other, and (iii) identify factors affecting browsing trees and shrubs in this protected area, such as tree characteristics (e.g., dbh and tree height), microhabitat features (e.g., covers of trees, shrubs, and herbs), and management actions (e.g., water point, fence, and track). Increasing knowledge on the aforementioned axes would help determine at which period of the year and in which forest areas the release of Cuvier's gazelles in the wild is most appropriate. The TR, as any enclosure, would offer an opportunity to consolidate our knowledge on this vulnerable gazelle in North Africa.

Acknowledgements We thank M. Lehcen for helping during the field work. We also thank the two anonymous reviewers and the Editor of the European Journal of Wildlife Research for commenting on an earlier version of the manuscript. This work complies with the current Moroccan laws as it is based on simple field observations without any experiment or prejudice to the animals studied.

\section{Declarations}

Conflict of interest The authors declare no competing interests.

\section{References}

Abaigar T, Cano M, Espeso G, Ortiz J (1997) Introduction of Mohor Gazelle (Gazella dama mhorr) in Bou-Hedma National Park. Tunisia Int Zoo Yearb 35:311-316

Abaigar T, Cano M, Sakkouhi M (2005) Evaluation of habitat use of a semi-captive population of Cuvier's gazelles Gazella cuvieri following release in Boukornine National Park. Tunisia Acta Theriologica 50(3):405-415

Abaigar T, Rodriguez-Caballero E, Martinez C, Amhaouch A, Samlali ML, Aparicio F, El Balla T, Essalhi A, Fernandez J, Garcia F, Haya M, M'Bareck A, M'Bareck H, Gonzalez LM, Fernandez de Larrinoa $\mathrm{P}$ (2019) The first reintroduction project for mhorr gazelle (Nanger dama mhorr) into the wild: knowledge and experience gained to support future conservation actions. Glob Ecol Conserv 19:e00680

Ait Baamrane MA, Shehzad W, Ouhammou A, Abbad A, Naimi M, Coissac E, Taberlet P, Znari M (2012) Assessment of the food habits of the Moroccan Dorcas Gazelle in M'Sabih Talaa, West Central Morocco. Using the trnL Approach Plos ONE 7(4):e35643

Ait Baamrane MA, Znari M, Loggers C, El Mercht S, Naimi M (2013) Demographic decline of the last surviving Moroccan dorcas gazelles Gazella dorcas massaesyla in M'Sabih Talaa Reserve. Morocco Oryx 47(4):578-583

Ait Baamrane MA, Znari M, Bellout S (2017) Evaluation du régime alimentaire de la Gazelle dorcas du Maroc Gazella dorcas massaesyla dans la réserve M'Sabih Talaa par analyse microhistologique. Go-South Bull 14:125-132

Arbouche Y, Arbouche HS, Arbouche F, Arbouche R (2012) Valeur fourragère des espèces prélevées par Gazella cuvieri Ogilby, 1841 au niveau du Djebel Metlili (Algérie). Arch Zootec 61(233): $145-148$

Benamor N, Bounaceur F, Baha M, Aulagnier S (2019) First data on the seasonal diet of the vulnerable Gazella cuvieri (Mammalia: Bovidae) in the Djebel Messaâd forest, northern Algeria. Folia Zool 68(4):253-260

Beudels RC, Devillers P, Cuzin F (2013) Gazella cuvieri Cuvier's gazelle (Atlas gazelle, Edmi gazelle). In: Kingdon J, Hoffmann M (eds) Mammals of Africa, vol VI. Pigs, Hippopotamus, Chevrotain, Giraffes. Deer and Bovids. Bloomsbury Publishing, London, pp 349-352

Borkowski J, Dobrowolska D, Dabrowski W, Banul R, Załuski D (2017) Young conifer stands form a deer browsing refuge for an oak admixture: silvicultural implications for forest regeneration under herbivore pressure. Eur j Forest Res 136:787-800

Bouredjli HA (1989) Eléments d'écoethologie de la gazelle de Cuvier: Gazella cuvieri (Ogilby, 1841) dans la réserve naturelle de Mergueb (M'Sila) et son statut en Algérie. Engineering thesis, Institut National Agronomique, El Harrach, Algeria

Breslau B, Polak T, Shalmon B, Groner E (2020) Evidence of browsing pressure on the critically endangered Acacia gazelle (Gazella acaciae). J Arid Environ 173:104019

Campbell P (1997) A note on growing season and food habits of mountain gazelles and Nubian ibex in Saudi Arabia. J Arid Environ 36:705-709

Chahrazed G, Dhaouia AS (2013) Étude du régime alimentaire de la gazelle de Cuvier dans la wilaya de Tiaret. Université Ibn Khaldoun, Tiaret, Mémoire Ir. d'État en Sciences Biologiques, p 90

Chebli Y, El Otmani S, Chentouf M, Hornick JL, Bindelle J, Cabaraux JF (2020) Foraging behavior of goats browsing in Southern Mediterranean Forest Rangeland. Animals 10:196

Chevrier T, Saïd S, Widmer O, Hamard JP, Saint-Andrieux C, Gaillard JM (2012) The oak browsing index correlates linearly with roe deer 
density: a new indicator for deer management? Eur $\mathrm{j}$ Wildl Res $58: 17-22$

Cristobal I (2006) Dieta invernal de tres especies de ungulados silvestres en un ecosistema mediterraneo. $\mathrm{PhD}$ thesis, Universidad de Castilla-La Mancha, Spain

Cuzin F (2015a) Plan de Gestion pour les populations sauvages de Gazelle de Cuvier (Gazella cuvieri). Direction Régionale des Eaux et Forêts et de la Lutte contre la Désertification du SudOuest/Agadir, GIZ. 32p

Cuzin F (2015b) Plan de gestion de la réserve de Tergou (Parc National d'Oulmès). GIZ Maroc. $19 \mathrm{pp}$

De Smet K (1991) Cuvier's Gazelle in Algeria. Oryx 31:99-104

Dray S, Dufour AB (2007) The ade4 Package: implementing the duality diagram for ecologists. J Stat Sofw 22

Gil-Sánchez JM, Herrera-Sanchez J, Alvarez B, Arredondo A, Bautista J, Cancio I, Castillo S, Diaz-Portero MA, de Lucas J, McCain E, Perez J, Rodriguez-Siles J, Saez JM, Martinez-Varderrama J, Valenzuela G, Qninba A, Virgos E (2016) Evaluating methods for surveying the Endangered Cuvier's gazelle Gazella cuvieri in arid landscapes. Oryx 51(4):648-655

Goodman P.S. (1975) The relation between vegetation structure and its use by wild herbivores in a riverine habitat. M. Sc. thesis, University of Zimbabwe.Grettenberger J (1987) Ecology in the dorcas gazelle in the northern Niger. Mammalia 51(4):527-536

Grettenberger J, Newby JE (1986) The status and ecology of the dama gazelle in the aïr and ténéré national nature reserve. Niger Biol Conserv 38(3):207-216

Hanane S, Magri N (2016) Post-release habitat utilization by Francolinus bicalcaratus ayesha, a critically endangered endemic subspecies to Morocco: implications for optimizing future release programs. Bird Conserv Int 26:323-326

Haraz M (2020) Diagnostic écologique et socio-économique pour l'élaboration d'un plan de gestion du SIBE El Harcha (Oulmès). Mémoire de $3^{\text {ième }}$ cycle. Ecole Nationale Forestière d'Ingénieurs. $212 \mathrm{pp}$

Hygnstrom S, Skelton P, Josiah S, Gilsdorf J, Virchow D, Brandle J, Jayaprakash A, Eskridge K, Vercauteren K (2009) Whitetailed deer browsing and rubbing preferences for trees and shrubs that produce nontimber forest products. HortTechnology 19(1):204-211

Ismaili B, Diouri M, Ouijja A (2018) Getting the dietary knowledge to restore a missing species: seasonal diet of Atlas deer Cervus elaphus barbarus in Tazekka National Park, Morocco. Wildl Biol wlb.00387
IUCN (2018) Stratégie et plan d'action pour la conservation de la gazelle de Cuvier (Gazella cuvieri) en Afrique du Nord 20172026. UICN Gland, Suisse et Malaga, $42 \mathrm{pp}$

Legendre P, Legendre L (1998) Numerical ecology. Elsevier Science, Amsterdam

Loggers C (1991) Forage availability versus seasonal diets, as determined by fecal analysis, of dorcas gazelles in Morocco. Mammalia $55: 255-267$

Mahenya O, Ndjamba J, Mathisen K, Skarpe C (2016) Giraffe browsing in response to plant traits. Acta Oecol 75:54-62

Mendiburu F (2010) Agricolae: Statistical Procedures for Agricultural Research. R Package Version 1:1-8

Nordengren C, Hofgaard A, Ball J (2003) Availability and quality of herbivore winter browse in relation to tree height and snow depth. Ann Zool Fennici 40:305-314

Quantum GIS Development Team (2017) QGIS Geographic Information System, Version 2.18.14-Las Palmas. Open Source Geospatial Foundation, Chicago

R Core Team (2018) A language and environment for statistical computing. R Foundation for Statistical Computing, Vienna. https:// www.R-project.org

Ramzi H, Qarro M, Zine El Abidine A, Abrioui A (2018) Conservation d'une population de mouflon à manchettes (Ammotragus lervia Pallas, 1977) (Mammalia, Bovidae) dans un espace clos : cas de la réserve d'Amassine dans le Haut-Atlas (Parc national du Toubkal, Maroc). Revue D'ecologie (terre Et Vie) 73(4):474-491

Sellami M (1999) La Gazelle de CuvierGazella cuvieri(Ogilby,1841) en Algérie. Statut et premiers éléments d'écologie, données sur le régime alimentaire dans la réserve naturelle de Mergueb (M‘Sila). Doctoral Thesis, Institut National Agronomique,Alger, Algeria.

Talbi K (1989) Etude éco-éthologique de la Gazelle du Cuvier (Gazella cuvieri, Ogilby 1841) dans la zone de Djebel El Achch, Wilaya de Saïda. Magister thesis, Institut National Agronomique, Alger, Algeria

Wallach A, Shanas U, Inbar M et al (2009) Feeding activity and dietary composition of roe deer at the southern edge of their range. Eur j Wildl Res 56:1-9

Wickham H (2016) ggplot2: Elegant Graphics for Data Analysis. Springer-Verlag, New York

Publisher's Note Springer Nature remains neutral with regard to jurisdictional claims in published maps and institutional affiliations. 